\title{
Learning Styles and Teaching Styles in College English Teaching
}

\author{
Mai Zhou \\ School of Foreign Languages, Zhejiang Gongshang University \\ 18 Xue Zheng Street, Hangzhou 310018, China \\ E-mail: zhoumai6993@sohu.com
}

\begin{abstract}
Students preferentially take in and process information in different ways: by seeing and hearing, reflecting and acting, reasoning logically and intuitively, analyzing and visualizing. Teaching methods also should vary accordingly. How much a student can learn is also determined by the compatibility of the student's learning styles and the teacher's teaching styles. It is important for teachers to know their learners' preferred learning styles because this knowledge will help teachers to plan their lessons to match or adapt their teaching and to provide the most appropriate and meaningful activities or tasks to suit a particular learner group at different stages.
\end{abstract}

Keywords: Learning style, Teaching style, Related factors

\section{Introduction}

Many ESL teachers experience student resistance when they introduce an instructional activity in the classroom. Some students want more opportunities to participating in free conversations, expressing their wish towards a more communicatively oriented approach. On the other hand, there are those who would prefer more emphasis on grammar teaching. We believe that the teacher, in making decisions regarding the type of activities to conduct in a language classroom, should take into account such learner diversities.

Learning styles play a vital role in students' learning process. Colleges and universities today show an increasing disparity between faculty and students, between teacher and learning. What suffers as a consequence is the learning process itself and the natural differences in learning patterns exhibited by new students are often interpreted by faculty as deficiencies. What may be happening, then, is a fundamental "mismatch" between the preferred styles of faculty and those of students. It is always important for teachers to teach this to their students. Teachers spare no efforts to refine their own teaching methods, keep on informing the students of various learning approaches, for example, how to build up word power, how to improve reading ability, etc. However, they forget one thing, the most important one, which one suits them most. Students won't take the approach recommended by the teacher, and apply that to their learning practice. As a result, teachers are supposed to figure out their students' learning styles - internally preferred learning styles, then the teaching styles can be compatible with the learning styles.

\section{Previous Study of Learning Styles}

Learning styles have profound effects on material processing, exercises designing, teachers' instruction options, performance assessments. Educators must place emphasis on intuition, feeling, sensing, and imagination, in addition to the traditional skills of analysis, reason, and sequential problem solving. Teachers should design their instruction methods to connect with all learning styles, using various combinations of experience, reflection, conceptualization, and experimentation. Instructors can introduce a wide variety of experiential elements into the classroom, such as sound, music, visuals, movement, experience, and even talking. Teachers should employ a variety of assessment techniques, focusing on acquiring the essential language skills. Generally speaking, the learning-style research can be divided into three major categories: cognitive learning styles, sensory learning styles, and personality learning styles.

\subsection{Definitions of learning styles}

To apply learning styles theory to English learning and teaching, we must know what learning style is. Learning has taken place when we observe a change of learner behavior resulting from what has been experienced. Similarly, we can recognize the learning style of an individual student only by observing his overt behavior. Learning style is a consistent way of functioning that reflects the underlying causes of learning behavior (Keefe, 1987). Learning styles are internally basic characteristics of individuals for the intake or understanding of new information.

Keefe (1991) describes learning style as both a student characteristic and an instructional strategy. As a student characteristic, learning style is an indicator of how a student learns and likes to learn. Each learner has distinct and consistent preferred ways of perception, organization and retention. These learning styles are characteristic, cognitive, affective, and physiological behaviors that serve as relatively stable indicators of how learners perceive, 
interact with and respond to the learning environment (Keefe, 1-87). Students learn differently from each other (Price, 1977). Talmadge and Shearer (1969) have determined that learning styles do exist. Their study shows that the characteristics of the "content of a learning experience are a critical factor affecting relationships that exist between learner characteristics and instructional methods. Reiff (1992) claims that styles influence how students learn, how teachers teach, and how they interact. Each person is born with certain preferences toward particular styles, but these preferences are influenced by culture, experience and development.

\subsection{The classification of learning styles}

A learning style is multidimensional (Kinsella, 1996). Its elements can be classified into five stimulus categories: environmental elements (sound, light, temperatures, design), emotional elements (motivation, persistence, responsibility), physical elements (perception, intake, time, mobility), sociological elements (self, partner, team, mentor, varied), and psychological elements (global/analytical, impulsive/reflective) (Reiff. 1992). Clearly, learning styles include not only the cognitive domain, but also the affective and physiological domains (Oxford, Hollaway. Horton-Murillo, 1992).

Generally speaking, the learning-styles can be divided into three major categories: cognitive learning styles, sensory learning styles, and personality learning styles. Cognitive learning styles include field-independent/field-dependent learning styles, analytic/global learning styles, reflective/impulsive learning styles and Kolb experiential learning model. Sensory learning styles also fall into the following four sub-styles: auditory learners, visual learners, tactile learners and kinesthetic learners. Temperament learning styles include Myers-Briggs temperament styles, tolerance of ambiguity styles, right-and left-hemisphere learners.

\subsection{Factors related to learning styles}

Research into learning styles have moved through stages of evolutionary development. The first wave of research was conducted in Sweden using qualitative methods with small samples (Marion \&saljo,1976). From these early beginnings, subsequent researchers developed learning style inventories. Learning style inventories use self-report instruments that are distributed on mass to students to establish their learning styles. The use of inventories in establishing learning styles of large groups of students signaled a shift from qualitative to quantitative research methods. Essentially the shift to qualitative methods allowed researchers to perform data reductions and statistical examinations of larger sample sets with the view of advancing knowledge. Regardless of methodological approach, these studies have collectively revealed that learning styles have an impact on learning outcomes, furthermore background characteristics, such as age, gender, personality, hemispheric dominance, educational background are known to have an impact on learning style. In order to improve the quality of learning outcomes, it would be appropriate for educators to devise specific strategies in an effort to enhance learning outcomes for students with different characteristics.

\subsection{Learning styles and learning strategies}

The term language learning strategy has been defined by many researchers. Wenden and Rubin (1987:19) define learning strategies as "... any sets of operations, steps, plans, routines used by the learner to facilitate the obtaining, storage, retrieval , and use of information," Richards and Piatt (1992: 209) state that learning strategies are "intentional behavior and thoughts used by learners during learning so as to better help them understand, learn, or remember new information, Faerch Claus and Casper (1983:67) stress that a learning strategy is "an attempt to develop linguistic and sociolinguistic competence in the target language." According to Stern (1992: 261), "the concept of learning strategy is dependent on the assumption that learners consciously engage in activities to achieve certain goals and learning strategies can be regarded as broadly conceived intentional directions and learning techniques. All language learners use language learning strategies either consciously or unconsciously when processing new information and performing tasks in the language classroom. Since language classroom is like a problem-solving environment in which language learners are likely to face new input and difficult tasks given by their instructors, learners' attempts to find the quickest or easiest way to do what is required, that is, using language learning strategies is inescapable. In short, learning strategy is an external skill that learners use, often consciously, to improve their learning.

\section{Teaching College English according to students' learning styles}

\subsection{Lesson planning in accordance with learning styles}

In all academic classrooms, no matter what the subject matter is, there will be students with multiple learning styles and students with a variety of major, minor and negative learning styles. An effective means of accommodating these learning styles is for teachers to change their own styles and strategies and provide a variety of activities to meet the needs of different learning styles. Then all students will have at least some activities that appeal to them 
based on their learning styles, and they are more likely to be successful in these activities, Hinkelman and Pysock (1992), for example, have demonstrated the effectiveness of a multimedia methodology for vocabulary building with Japanese students. This approach is effective in tapping a variety of learning modalities. By consciously accommodating a range of learning styles in the classroom in this way, it is possible to encourage most students to become successful language learners.

\subsection{Altering teaching style to create teacher-student style matching}

The prospect of altering language instruction to somehow accommodate different learning styles might seem forbidding to teachers. This reaction is understandable, Teaching styles are made up of methods and approaches with which teachers feel most comfortable; if they try to change to completely different approaches, they would be forced to work entirely with unfamiliar, awkward, and uncomfortable methods. Fortunately, teachers who wish to address a wide variety of learning styles need not make drastic changes in their instructional approach, Regular use of some of the instructional techniques given below should suffice to cover some specified learning style categories.

1) Make liberal use of visuals. Use photographs, drawings, sketches, and cartoons to illustrate and reinforce the meanings of vocabulary words. Show films, videotapes, and live dramatizations to illustrate lessons in text.

2) Assign some repetitive drill exercises to provide practice in basic vocabulary and grammar, but don't overdo it.

3) Do not fill every minute of class time lecturing and writing on the blackboard. Provide intervals for students to think about what they have been told; assign brief writing exercises.

4) Provide explicit instruction in syntax and semantics to facilitate formal language learning and develop skill in written communication and interpretation.

\subsection{Fostering guided style-stretching}

Learning style is a consistent way of functioning which reflects cultural behavior patterns and, like other behaviors influenced by cultural experiences, may be revised as a result of training or changes in learning experiences. The following are examples of teaching activities that guide students to alter their learning behaviors, stretch their learning styles and enable them to improve their language performance.

1) Groups of four or five learners are given cards, each with a word on it. Each person describes his word in the foreign language to the others in the group without actually using it. When all students have described their words successfully, the students take the first letter of each and see what new word the letters spell out. (Puzzle parts might also depict objects in a room; in this case, when all the words have been guessed, the group decides which room of the house has been described.)

2) Class members are placed in pairs or in larger groups. Each student has a blank piece of paper. He listens to his partner or the group leader who has a picture to describe (the teacher can provide the picture or students can choose their own). As his partner describes the picture, the student tries to draw a rough duplicate according to the description he hears.

\subsection{Providing activities with different grouping}

In a class made up of students with various learning styles and strategies, it is always helpful for the teacher to divide the students into groups by learning styles and give them activities based on their learning styles. This should appeal to them because they will enjoy them and be successful. For example, the group made up of the extroverted may need to express some ideas orally in the presence of one or many class members. On the other hand, the group made up the introverted may need some encouragement to share aloud and may want the safety of jotting down a few notes first and perhaps sharing with one other person before being invited or expected to participate in a group discussion.

No matter how students are to be grouped, teachers should make a conscious effort to include various learning styles in daily lesson plan. One simple way to do this is to code the lesson plans so that a quick look at the completed plan shows if different learning styles have been included. Putting "A" or "V" beside activities that denote whether they are primarily appealing to the analytic learner or the visual learner will serve as a reminder that there is a need for mixture of both kind of activities. Meanwhile, simply designating various parts of the lesson plan with letters (I for individual, P for pair, SC for small group, LG for large group) and other symbols reminds the teacher to pay attention to learning styles. If the coding system is used on a regular basis, it becomes very natural to think in terms of providing the setting and the activities by which all learners can find some portion of the class that particularly appeals to them.

\subsection{Consideration of college English learners}

An overwhelming majority of college students are adults, and they have their own characteristics. Adult learners are 
self-directed and independent, and they are able to draw on a reservoir of accumulated experience as a rich resource in learning, are aware of their learning needs and want to apply skills and knowledge to real-life problems and tasks. Their previous learning experience does have impact on their learning styles. Students usually make contrasts and comparisons between their former English teachers' teaching practice and the new one's. Even if the new one's teaching is more reasonable and appealing, their former teacher's teaching impact still lasts. In China, college students have no or little real-life experience, therefore, they don't have a clear picture of their needs required by their future career. English teachers are expected to inform their students of what to learn and the language requirements by the society.

\subsection{Teaching techniques involved in learning styles}

Traditionally, the teaching of EFL in China is dominated by a teacher-centered, book-centered, grammar-translation method and an emphasis on mechanical memory. These traditional language teaching approaches have resulted in a number of typical learning styles, with visual learning being one of them. A teacher must design her lesson plan around her students. After you know the students learning styles, you should set goals for your teaching strategies. This requires you to differentiate instruction through use of the learning styles. Ideally you want to incorporate all of the learning styles so that each student may learn in a way that suits them best for the day.

Studies show that matching teaching styles to learning styles can significantly enhance academic achievements, student attitude and student behavior at the college level. This is not to say that the best thing one can do for one's students is to use their preferred modes of instructions exclusively. A point no educational psychologist would dispute is that students learn more when information is presented in a variety of modes than when only a single mode is used. The point is supported by a research study carried out several decades ago, which concluded that students retain $10 \%$ of what they read, $26 \%$ of what they hear, $30 \%$ of what they see, $50 \%$ of what they see and hear, $70 \%$ of what they say and $90 \%$ of what they say as they do something (Stice,1987). The following are some techniques employed in my teaching practice:

1) Provide a balance of concrete information (data, facts, experiments and results) and abstract concepts (principles, theories).

2) Balance material that emphasizes practical problem-solving methods with material that emphasizes fundamental understanding.

3) Use pictures, graphs and simple sketches liberally, during and after the presentation of verbal material. Show films or provide demonstrations, if possible.

iv. Don't fill every minute of class time lecturing and writing on the blackboard. Set aside intervals-however brief - for students to learn what have been told on their own. Raise questions and problems to be worked on by students in a small group,

5) Talk to students about learning styles, both in advising and in class. Students are reassured to find their academic difficulties may not all be due to personal inadequacies. Explaining to students how they learn most efficiently may be an important step in helping them reshape their learning experiences so that they can be successful.

6) Try to design some activities which involve students, senses as many as possible, using all the senses to help improve English learning. For example, relatively long passage dictations, and games, which require students to write down what they are told by their classmates, who already have learnt that by heart.

7) Encourage students to learn English online, such as, post writing assignments through e-mail, read materials given online (the students in the experimental class use the new horizon college English book, a web-assisted textbook).

8) Motivate learning. As much as possible, teach new material in the context of situation to which students can relate in terms of their personal experiences, rather than simply as more material to memorize.

Teachers confronted with this list of techniques might feel that is impossible to do all that in the English Class and still cover the syllabus and requirements. The idea, however, is not to adopt all the techniques at once but rather to pick several that look feasible and try them on an occasional basis; and try one or two more later in class. In this way a teaching style that is both effective for students and comfortable for teachers will evolve naturally, with a potentially dramatic effect on the quality of learning.

\section{Conclusion}

Mismatching may be appropriate so that students' experiences help them to learn in new ways and to bring into play ways of thinking and aspects of the self not previously developed. Any mismatching. however, should be done with sensitivity and consideration for students, because the experience of discontinuity can be very threatening, 
particularly when students are weak in these areas. Knowledge of learning style can thus help faculty design experiences appropriate for students in terms of matching or mismatching and enable them to do so thoughtfully and systematically.

Learning a foreign language without guidance is similar to sailing without a good map. When teachers are aware of the importance of learning styles, they can provide a good map to their students. It's time for teachers to seek a reasonable way to teach English so that students can swim in open seas.

\section{References}

Feng Zhiwei. (1999). Applied Linguistics Overview. Guangzhou: Guangdong Educational Press. pp.45-46.

Gui Shichun. (1992). Psychology of English Learners in China. Changsha: Hunan Educational Press. pp.21-30.

Reid . J. (2002). Learning styles in the ESL-EFL Classroom. Beijing: Foreign Language Teaching and Research Press. pp. 81-84.

Stern, H. H. (1983). Fundamental Concepts of Language Teaching. London: Oxford University Press. pp13-14. 